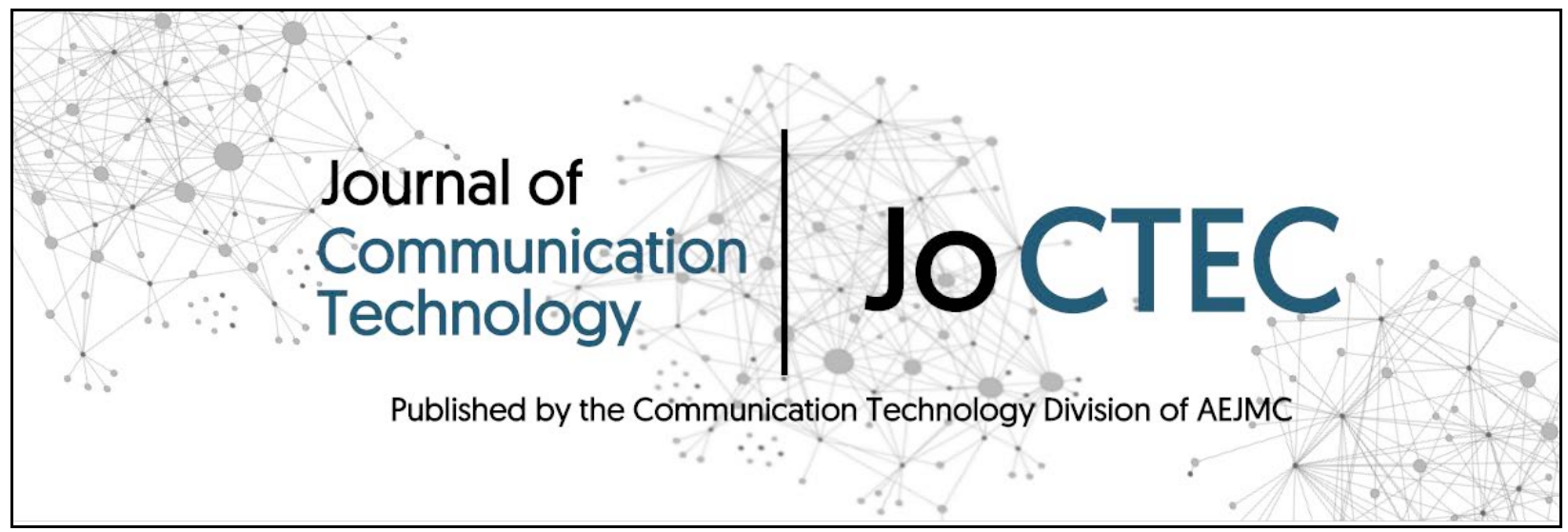

The Calibration Problem: ICT Complexity and Average User Competencies

\author{
Erik P. Bucy \\ Marshall and Sharleen Formby Regents Professor of Strategic Communication \\ College of Media and Communication \\ Texas Tech University
}

Correspondence:

806-834-3346

erik.bucy@ttu.edu

Original manuscript accepted for publication in

Journal of Communication Technology

Published by the Communication Technology Division of the Association for Education

in Journalism and Mass Communication

DOI: 10.51548/joctec-2018-003 


\section{The Calibration Problem: ICT Complexity and Average User Competencies}

When the World Wide Web opened the networked infrastructure of the Internet to use on a large scale, much hope was pinned on the new medium's potential to evolve into an "information superhighway" where an endless array of facts would be at the public's beck and call for edification and self-enlightenment. Visionary technologists had imagined similar systems decades earlier_-"wholly new forms of encyclopedias . . . ready made with a mesh of associative trails running through them," as Vannevar Bush (1945, para. 65) described his Memex concept. Much popular speculation also focused on the politically empowering role of information and communication technologies (ICTs) to serve as organizing agents for social change (Grossman, 1995; Rheingold, 2002). Although, some did warn about the "disappointing realities" of online message flows, including their susceptibility to spreading rumor and valorizing trivia, to lending credibility to extreme opinions, and to circulating false information at cybernetic speeds (Stoll, 1995, pp. 218-224).

At the same time, researchers have documented the numerous challenges facing individual users in complex information environments that argue against the view of ICTs as a liberating and rationalizing force in society (see Bucy \& Newhagen, 2004; van Dijk, 2005, 2012). First, effective use of ICTs for social, educational, and political action requires not only physical access to digital technologies and motivation to use them but a succession of skills that include operational, informational, and strategic abilities to leverage network capacities. The ability to search, process, and utilize information in complex digital spaces "cannot be taken for granted," van Dijk (2005, p. 73) cautioned. "These skills have to be learned" (van Dijk, 2005, p. 73).

Typical user orientations toward information and communication technologies, however, suggest that motivation to learn is limited. Surveys of baseline digital skills of even "universally wired" groups of Internet users show considerable variation in user competence, number of network access points, time spent online, and self-assessed ability (Hargittai, 2010). Digital 
skills are also lower for less privileged segments of society, and lower perceived skill significantly affects online behavior and types of uses to which less skilled users will put the medium (Hargittai \& Shafer, 2006).

Key to understanding the nature of these challenges is the level of analysis at which arguments about technological influences are made. In the case of political empowerment, a broad perspective is often embraced that reflects a social level of analysis, where technology seems to enable collective movements to achieve desired ends-even if such success means primarily delivering on a sense of shared community (see Papacharissi, 2015). Castells (2007, 2009) cites the advent of several trends, including Internet-based fundraising and mobilization, organizing via mobile media, and the appearance of autonomous communication networks supported by the Internet and wireless communication not under the control of dominant media players as evidence of a new phase of counter-power in the network society. Bennett (2013) further examines the organization of power in communication-based networks, showing how the logic of "connective action" is coordinated using inclusive discourses, such as the "We Are the 99\%" slogan that traveled through social media during the Occupy Wall Street protests. $^{1}$

When describing successful collective action efforts enabled by technology, mobilization enthusiasts are largely extolling the sociology of mass movements. In effect, they are documenting the achievements of a new class of information elites-activists who harness the democratizing potential of technology to devise workarounds to entrenched power structures; they are not, however, describing the abilities or inclinations of average users. Average, or end, users now more often serve as targets of online communication campaigns, particularly on social media, than they do as original content providers or political organizers. As observed elsewhere (Bucy \& Zelenkauskaite, 2014; Zelenkauskaite \& Bucy, 2016), the growing capacity of networked systems to track, collate, and parse online behaviors exercises power over and discriminates against average users by extracting their data for marketing purposes (typically without their full consent and understanding) and then bombarding them with tailored 
advertising and unsoliticed persuasive messaging. The quality of message flows for the average user in the networked environment is one of besieged inundation rather than liberating autonomy.

\section{Asymmetric message flows}

Nowhere was this concept more apparent than during the 2016 U.S. presidential election, where the onslaught of dubious information sources, fake news reports, and botgenerated content on social media platforms_dubbed "computational propaganda" (see Markoff, 2016)—-taxed the ability of even dedicated fact-checkers (Dale, 2016). ${ }^{2}$ This unprecedented situation presented a problem familiar to psychologists who have studied information acceptance. First, most citizens could not contend with the pace and volume of political information that would go viral—it is far easier to just click on or forward a piece of outrageous or salacious information than to verify its authenticity first, particularly if that story reinforces a stereotype. Hence, a Buzzfeed analysis found during the General Election that the 20 top-performing false election stories from hoax sites and hyperpartisan blogs (e.g., "Just Read the Law: Hillary Is Disqualified From Holding Any Federal Office") generated 1.3 million more shares, reactions, and comments on Facebook than the 20 best-performing legitimate election stories from major news websites-8.7 million compared to 7.4 million (Silverman, 2016).

Second, even if an effort was made to verify suspect content, there is a psychological tendency grounded in evolutionary theory to accept initial claims as true first before then deciding to reject them (Gilbert, Krull, \& Malone, 1990), so the initial acceptance of bogus information often wins out over well-intentioned but insufficient efforts to correct false claims.

Against this backdrop of asymmetrical information flows-flows that represent the exercise of network power-the average user is increasingly defenseless to turn back the information tide and exercise a meaningful degree of control over the quality of their news 
intake. The inability of users is paradoxical because interactive media are supposed to give users more control over their media experiences. In many ways they do, enabling customized browsing sessions and enhancing entertainment experiences especially (Kalyanaraman \& Wojdynski, 2015). However, this base-case scenario does not present when it comes to news, where interface affordances may give users a sense of feeling closer to newsworthy developments but often leave them feeling confused (Bucy, 2004). Engaging in "second screen" activity through a mobile device, as when viewers of presidential debates tweet to other viewers in real time, may enhance a sense of participation, but multitasking typically comes with the cognitive cost of not retaining much information (Ophir, Nass, \& Wagner, 2009). As a result, users have difficulty navigating complex digital environments and sorting out fact from opinioneven seeing more risk if reader comments underneath an online news story are infused with enough incivility or negativity (Anderson, Brossard, Scheufele, Xenos, \& Ladwig, 2013).

This pollution of the information environment, increasingly planned by strategic actors operating in the policy sphere with the goal of diffusing dissent, undermining science claims, casting doubt on established facts, or influencing elections (Markoff, 2016; Wertime, 2016), is not limited to online media either. The totality of opinion journalism, whether on cable "news" networks, partisan blogs, or talk radio, traffics in a similar politics of assertion and confrontation over reason (see Mutz, 2015).

In the pre-cybernetic and pre-opinion news era (roughly, the time prior to the rise of the World Wide Web, conservative talk radio, and the Fox News Channel), ${ }^{3}$ media personnel involved in producing the printed newspaper and daily newscast made editorial decisions on behalf of audiences and insulated everyday citizens from having to search for and verify important developments themselves. Granted, this coverage was not always as enterprising or hard-hitting as it might have been (Fallows, 1996; Hertsgaard, 1989), but surveillance and correlation of different elements of society were among the news media's major acknowledged functions (Lasswell, 1948) and few questioned the central role of the press in providing "a 
complete and honest account of the day's events." As digital media have supplanted the printed press and the universe of television content has exploded, that burden of surveillance-of information search, curation, and verification—has largely devolved onto the individual, who must now navigate an expanding universe of content choices and delivery platforms, deciding what is important, believable, and true and what is not. ${ }^{4}$

Thus, social level, and largely anecdotal, arguments about power redistribution through networked media are seriously challenged when brought down to the level of the individual user, where skill deficiencies, lack of training, usage gaps, uneven motivation, and other barriers to full media access prevail (van Dijk, 2005; see also Hargittai, 2010; Hargittai \& Shafer, 2006; Newhagen \& Bucy, 2004). Unlike earlier analog media, which demanded a more straightforward (though nontrivial) kind of user expertise-reading in the case of newspapers, the ability to parse oral communication in the case of radio, visual acumen and an appreciation for dialog and drama in the case of television or film —a wide range of cognitive and technical abilities must be brought to bear to successfully navigate networked spaces and make gainful use of online resources. In study after study, the average user does not display the high degree of information efficacy, political interest, or technical ability that network mobilization advocates assume. If you are not an activist offline, you are unlikely to become one online.

Indeed, users are empowered to make full use of new communication technology only to the extent that they are cognitively, motivationally, and technically able. Even assuming motivation, the cognitive and technical barriers to full media access are considerable. Unlike television, the interconnected, multimodal, and software-dependent quality of networked communication technologies-their integrative or remedial properties, in the phrase of Bolter and Grusin (2000)—makes online media strikingly different from earlier, analog platforms in their degree of complexity. This complexity derives from the layered quality of network architecture, high degree of system adaptability by means of computer software, and unique affordances of different digital platforms. Together, networked media are characterized by 
distinct system functions, multiple traffic patterns or information flows, communication at different levels of analysis, and-through a proliferating number of digital devices-growing interface variation.

\section{Contrasting configurations of communication}

This veritable collision of qualities not surprisingly produces multiplicative and contrasting configurations of communication and interaction, a $4 \times 4 \times 4 \times 4$ conceptual matrix that remains beyond the reach of the average user to fully comprehend and leverage. Imagine here the difficulty of solving a Rubik's cube, only the challenge is not sequential and cannot be solved with a simple algorithm. First, communication even without technology can occur at four different levels of meaning: interpersonal, group, organizational, and mass. Through different applications and platform interfaces, the Web accommodates each of these levels, for example, through email, chat, teleconferencing, social media apps, company or department intranets, and mass media websites. Adding to the complexity, all four levels of communication can occur simultaneously on the same screen, depending on which application windows are open.

Thus, in the networked environment we start out with four levels of communication $(4 \times$ 1). But the Web, as a computationally based system, is capable of much more than communication. As December (1997) pointed out early in the networked era, the Web as a technological system facilitates at least four basic functions: communication, information exchange, interaction, and computation. Communication, which involves the exchange of meaning through the use of symbols or nonverbal signals between two or more people through the network, differs from information exchange, which is the dissemination and retrieval of stored data or knowledge. Interaction entails uses of the network for reciprocal exchanges aside from information, such as game play, activities in virtual worlds, or group interactions. Computation involves data processing, which the Web, even though we now think of it as a 
communication platform, still performs quite handily. Each function represents a distinct class of activity that, when combined together on a single distributed platform, endows the distributed network of servers supporting the Web more versatility and processing capacity than all other media platforms combined.

Crossing levels of communication with functions of the networked environment produces 16 unique information and communication configurations $(4 \times 4)$.

Within these contrasting levels of communication, interactional dynamics, and system functions, information and data traffic may flow in at least four distinct directions, as detailed by Bordewijk and van Kaam (1986) in their seminal discussion of information traffic patterns in teleinformation services. In their typology of data flows, they distinguish between four different patterns of exchange. The first, allocution, models a transmission process from a service center to an individual consumer or locality; this is the network's capacity to "push" content to users based on inputted preferences or collaborative filtering that determines your preferences based on transaction log data. Mostly, it represents a one-way flow of messages to the end user, combining "many of the traits of networks with those of broadcast" (Kelly \& Wolf, 1997, para. 11), Consultation, the inverse of allocation, reflects a dynamic where the service center only delivers information at the specific request of the consumer, as with queries to search engines, online encyclopedias, or medical reference sites. "Consultation requires more activity by the consumer than allocution, but also grants much more freedom in selecting the information required" (Bordewijk \& van Kaam, 1986, p. 577).

Perhaps the most troubling, and insidious, traffic pattern is registration, where the service center "no longer has the task of issuing information, but of collecting it" (Bordewijk \& van Kaam, 1986, pp. 579-580). At the most basic level, networked systems require users to establish log-in protocols and passwords before gaining access to services and increasingly require users to complete extensive credit type applications to gain full use, as with Apple's much reviled iTunes platform. In the process of using the service, or posting content to social 
media communities, user-generated content is captured as a matter of routine so that consumers can then be advertised to more efficiently. Even with simple Web browsing, cookies track user movements and compile browsing and purchasing histories that have utility to advertisers. Although recognized early on and heavily criticized as a practice (see Garfinkel, 2000; Rosen, 2001), extracting information from users in the process of providing services has become the primary function of most network destinations today.

The fourth traffic pattern, conversation, represents peer-to-peer communication where information-handling capacities are divided equally between two terminals, as with email, voice over Internet protocol (VoIP), chat or other short messaging services. Thus, varying traffic patterns add another layer of complexity onto networked media. Crossing levels of communication with functions of the networked environment and now information traffic patterns produces 64 unique information and communication configurations $(4 \times 4 \times 4)$.

Finally, each of these contrasting communication and information configurations, with their varying interactional dynamics, system functions, and data traffic flows, may be accessed and transacted over different hardware platforms, including desktop and laptop computers, tablet devices, and Internet-enabled mobile phones. The distinction here may seem trivialinterfaces mostly differ in size, right?-until consideration is given to the unique set of technical skills required to put each new device to strategic use, the demands of software upgrades and new models of use like "cloud computing," and the digital dexterity required to work seamlessly across the idiosyncrasies of screens large and small (not to mention differences and incompatibilities between Windows, Mac, and Android operating systems).

Crossing levels of communication with functions of the networked environment, information traffic patterns and, now, different hardware platforms through which users access and interact with content and other users produces 256 unique information and communication configurations $(4 \times 4 \times 4 \times 4)$. 
Hardware requirements constantly change and advance as well, requiring continuous investment in the means of physical access to take full advantage of system offerings. Hand a smart phone to a flip phone user and the device will seem exotic and inaccessible, barely resembling a phone at all. Updates and system design changes are now so routine and frequent that computer instruction manuals have become a quaint artifact of a bygone era-users must now teach themselves how the system operates and become autodidactic in their approach to technology. Self-learning provides a workable solution for some, but not all, users and turns the discussion about media access toward the question of motivation.

\section{Media access and motivation}

In Media Access: Social and Psychological Dimensions of New Technology Use, Bucy and Newhagen (2004) catalogued the skills, motivations, and psychological resources that audiences, whether conceived as citizens or consumers, must possess to strategically utilize new communication technologies. The old assumption, particularly concerning networked media adoption, was that physical access to computer hardware and telecommunications infrastructure was sufficient to resolve disparities in use. From a media access perspective, the problem instead needs to be considered in much broader human and technological terms. Importantly, a distinction needs to be made between having physical access to the Internet-or any networked medium — as a technology and being able to cognitively access and process the content that resides on it. Because of the multimodal character of content online-namely, the simultaneous interaction of text and images in a layered system that accommodates myriad contrasting configurations of communication and information traffic flows-"a broader range of psychological processes will have to be considered than has been the case for traditional mass media" (Newhagen \& Bucy, 2004, p. 13).

Using this observation as a departure point, next generation technology research should more explicitly take user skills into account as moderators of effects—not just to estimate 
computer expertise in the population but to investigate how expertise shapes and delimits online experiences. Research on videogame play, for instance, has shown that skill level not only determines how far users progress in gameplay but how much of the game world their characters see and amount of violence they encounter (Matthews \& Weaver, 2013). Higher skilled players perpetrate violence more often than lower skilled users, while lower skilled users more often suffer as the targets of violence-and express more frustration after game play (Nowak, Krcmar, \& Farrar, 2008). This frustration, the authors surmise, could either stem from repeated victimization within the game or having to learn the game mechanics, which together could cause disorientation and confusion, along with hostility toward the game environment. These results seem highly applicable and could serve as a metaphor for the broader experience of online search and content navigation more generally.

Skill level not only defines and circumscribes the experiences of users within digital environments, but it may also affect motivation to engage with technology in the first place. The social context of technology use, often overlooked in studies of usage gaps and digital divides, is another important consideration. Socioeconomic class, life circumstances, community infrastructure, and even expectations within families form a more durable and persistent class outlook toward ICTs than commonly assumed (Rojas, Straubhaar, Roychowdhury, \& Okur, 2004). Appropriating Bourdieu's notion of habitus or "dispositions that create durable and transposable practices and perceptions over a long process of social inculcation," Rojas and colleagues (2004, p. 114) identify a shared understanding or orientation toward technology ("technodisposition") that prevents young users in downtrodden communities from engaging with information technologies in ways that are personally empowering or useful. Despite such conventional remedies as free wifi, low-cost computing, wired schools and libraries, and other public access centers, facilitating social access to networked systems remains a daunting challenge. 
Some point to smartphone technology as the workaround to the thorny issues associated with full media access, or as it has been called in the human-computer interaction literature, universal usability (Shneiderman, 2000). In early 2015, Wired magazine pronounced that, "In less than two years, a smartphone could be your only computer" (Bonnington, 2015). Granted, in terms of convenience and versatility, there is a case to be made for the smartphone as a technology capable of "leapfrogging" the traditional computing platforms of desktops and laptops-particularly for social and entertainment needs. But even as new ways are found for the smartphone to facilitate communication and interface with other playback devices, their informational and computational power remains limited.

Settling for a mobile device over a true computing platform entails a tradeoff between convenience and power, a tradeoff that reinforces the average user's end user status. While their storage and processing capacities of mobile devices are growing, they are nowhere near as robust as full-size platforms and have far fewer capabilities. Although terminal emulators running on iOS and Android devices now make it possible to access mainframe systems remotely, the reduced memory and processing speeds of mobile compared to desktop devices compromises smartphones as input/output devices, making them difficult to work with on anything except smaller projects and files. Apps and mobile operating systems are similarly anemic compared to the fully featured operating systems and programs found on computers. "The handheld smartphone is a gutless wonder compared with the desktop machine," computer guru John Dvorak (2012, para. 2) declared a few years ago. "What we have is a touch-screen phone that has cloud access and can run some rudimentary code called 'apps."'

Granted, the smartphone of 2018 (e.g., Apple's iPhone X) is much more advanced than the smartphone of 2012 (e.g., the iPhone 5)—but so are the latest desktop and laptop computers. For the foreseeable future, then, computers will continue to run the technology table, presenting the familiar barriers to full media access. 


\section{User-to-system calibration}

A critical but often overlooked factor influencing whether users are positioned to make gainful use of interactive media is the degree to which their skills, motivations, and competencies are properly calibrated or congruent with the challenges presented by the medium (Hoffman \& Novak, 1996). Calibration is a particularly vexing problem with networked computing, which confronts the user with communication opportunities at a wide range of levels (from interpersonal to mass), across different devices, while encountering varying traffic patterns and interface demands. Online, the user enters a cognitively demanding setting marked by many different and contrasting configurations of communication (Morris \& Ogan, 1996; Newhagen \& Bucy, 2004).

Figure 1 illustrates how users with a high level of competency (the darkest circles along the bottom row) possess the skills necessary to benefit from just about any degree of ICT complexity. The vertical lines to the top row represent optimal calibration, while the solid angled lines represent adequate calibration or, at worst, a skills surplus. Sophisticated users are equipped to effectively engage with the most to the least complex technologies. However, lowend users (the lightest circles along the bottom row) have considerably less flexibility. As the diagram indicates, low-end users are able to take advantage of interactive media as long as the degree of complexity remains moderate. As the complexity level increases, a threshold is crossed and a miscalibration or skills deficit occurs (represented by the dashed angled lines). In this situation, low-end uses have the option of either improving their skills and meeting the technology at the required level of expertise or (perhaps more likely) abandoning their efforts altogether after a period of initial, frustrating use (see Bessiere, Ceaparu, Lazar, Robinson, \& Shneiderman, 2004). 
Figure 1: The calibration problem. Illustration of the degree to which user skills, motivations, and competencies may be (in)congruent with system demands.

\section{ICT Complexity}

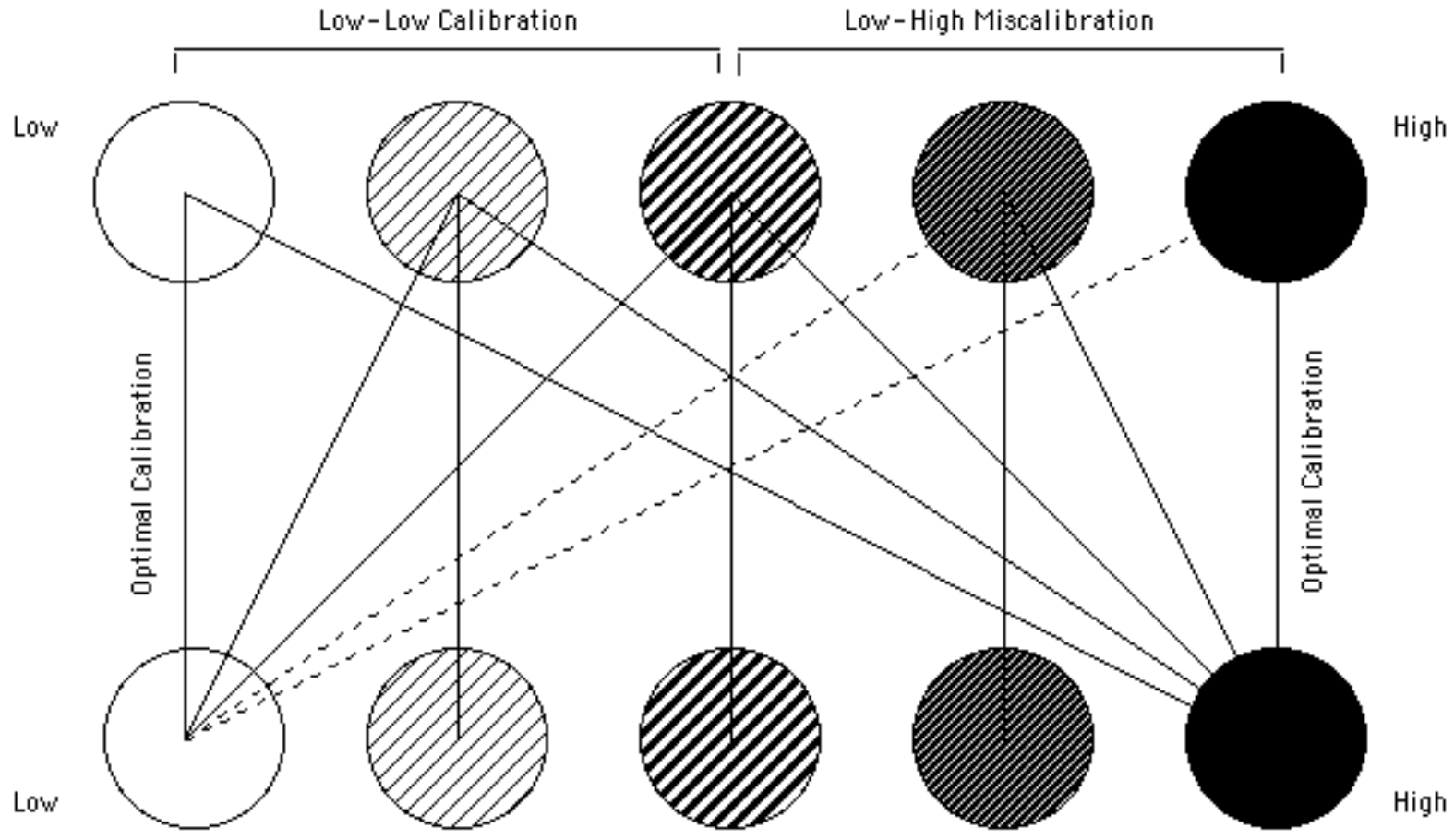

User Competencies

The flip side of the calibration problem is that sophisticated users, in the case of a skills surplus, may not feel sufficiently challenged by noninteractive media to give it their ongoing attention. As Hoffman and Novak (1996) comment in relation to computer-mediated environments (CMEs), "if network navigation . . . does not provide for congruence of skills and challenges, then consumers either become bored (i.e., their skills exceed the challenges) or anxious (i.e., the challenges exceed their skills) and either exit the CME or select a more (or less) challenging activity within it" (p. 60). Anecdotally, the popularity of interactive and participatory media, particularly among younger users, suggests that audience segments 
accustomed to interactive experiences come to expect a certain level of hands-on engagement and create it for themselves when it cannot be found in one medium alone (Jenkins, 2008). The resulting fracturing of attention has, according to media critics, caused content producers to create faster-paced, more visually oriented productions with a fragmented story structure intended to stave off restlessness (Gleick, 2000). ${ }^{5}$ Thus, the calibration problem associated with interactive media has implications for both sophisticated and unsophisticated users alike.

As this discussion of calibration issues suggests, future research into network technology effects should consider the ratio of user skills, motivations, and competencies to system challenges. Research should not be satisfied with merely identifying when a networked communication setting is perceived as challenging (although more work needs to be done in this area) but should also ultimately address the consequences of skills deficits, skills surpluses, and varying barriers to full media access.

In the case of an enduring miscalibration between user skills and system challenges, for example, the interactive technology may prevail and alienate average users from the Web's social and informational bounty. ${ }^{6}$ In his account of the rise of the network society, Castells (1996, p. 371) predicted increasing social stratification among users such that "the multimedia world will be populated by two essentially distinct populations: the interacting and the interacted, meaning those who are able to select their multidirectional circuits of communication, and those who are provided with a restricted number of prepackaged choices" or acted upon. The consequence of this disparity in technology use leads to what van Dijk $(2000,2005)$ identifies as a "usage gap" between different segments of the population, where well-placed users make far greater use of advanced applications at work, home, and school settings while misplaced users seek online amusement, game playing, and entertainment, and perhaps "infotainment" experiences. As computers continue to diffuse internationally, hardware penetration rates have risen but usage gaps have grown, with differences rising between simple and advanced information uses among different socioeconomic groups (van Dijk, 2005). 
The issues involved in processing content and successfully navigating networked systems should be familiar to communication technology researchers and we should take opportunities like this to remind policy makers of the challenges confronting ordinary users. Not every audience member is equally equipped to contend with the demands of networked media and the array of complex message flows swirling about and enveloping society. This presents a challenge to message producers, who cannot assume uniform competencies across different strata of the social order, and to communication scholars, who must remain cognizant that most members of the media audience do not even possess a college degree. The great promise of mass communication — to uplift and edify the masses—will only ever be partially realized if media producers, scholars, and critics continue to operate under the incorrect assumption that all audience members are highly sophisticated, civically and informationally engaged, technically literate, and textually oriented; they are not-and so we must understand and meet the mass audience where its skills and motivations are rather than where we wish them to be.

\section{References}

Anderson, A. A., Brossard, D., Scheufele, D. A., Xenos, M. A., \& Ladwig, P. (2013). The "nasty effect:" Online incivility and risk perceptions of emerging technologies. Journal of Computer-Mediated Communication, 19(3), 373-387.

Bennett, W. L., \& Segerberg, A. (2013). The logic of connective action: Digital media and the personalization of contentious politics. New York: Cambridge University Press.

Bessiere, K., Ceaparu, I., Lazar, J., Robinson, J., \& Schneiderman, B. (2004). Social and psychological influences on computer user frustration. In E. P. Bucy \& J. E. Newhagen (Eds.), Media access: Social and psychological dimensions of new technology use (pp. 91-103). Mahwah, NJ: Lawrence Erlbaum Associates. 
Beyer, Y., Enli, G. S., Maaso, A. J., Ytreberg, E. (2007). Small talk makes a big difference: Recent developments in interactive, SMS-based television. Television and New Media, 8(3), 213-234.

Bonnington, C. (2015, February 10). In less than two years, a smartphone could be your only computer, Wired. Retrieved from https://www.wired.com/2015/02/smartphone-onlycomputer/

Bolter, J. D., \& Grusin, R. (2000). Remediation: Understanding new media, rev. ed. Cambridge, MA: MIT Press.

Bordewijk, J. \& van Kaam, B. (1986). Towards a new classification of tele-information services. Intermedia, 14(1), 16-21.

Bucy, E. P. (2004). The interactivity paradox: Closer to the news but confused. In E. P. Bucy \& J. E. Newhagen (Eds.), Media access: Social and psychological dimensions of new technology use (pp. 47-72). Mahwah, NJ: Lawrence Erlbaum Associates.

Bucy, E. P., \& Newhagen, J. E. (2004). Media access: Social and psychological dimensions of new technology use. Mahwah, NJ: Lawrence Erlbaum Associates.

Bucy, E. P., \& Zelenkauskaite, A. (2014, October). Big Data and unattainable scholarship. In S. P. Gangadharan, V. Eubanks, \& S. Barocas (Eds.), Data and discrimination: Collected essays, pp. 21-25. Washington, DC: Open Technology Institute, New America Foundation. Retrieved from http://newamerica.org/downloads/OTI-Data-anDiscrimination-FINAL-small.pdf

Bush, V. (1945, July). As we may think. The Atlantic. Retrieved from http://www.theatlantic.com/magazine/archive/1945/07/as-we-may-think/3881/

Castells, M. (1996). The rise of the network society. Oxford: Blackwell.

Castells, M. (2007). Communication, power, and counter-power in the network society. International Journal of Communication, 1, 238-266. Retrieved from http://ijoc.org/index.php/ijoc/article/viewFile/46/35 
Castells, M. (2009). Communication power. New York: Oxford University Press.

Dale, D. (2016, October 19). Confessions of a Trump fact-checker. Politico. Retrieved from http://www.politico.com/magazine/story/2016/10/one-month-253-trump-untruths-214369

December, J. (1997). The World Wide Web unleashed, 4th ed. Carmel, IN: Sams Publishing.

Dvorak, J. C. (2012, December 4). Should we consider the smartphone a computer? PC magazine. Retrieved from http://www.pcmag.com/article2/0,2817,2412850,00.asp

Evans, E. J. (2008). Character, audience agency, and transmedia drama. Media, Culture, \& Society, 30(2), 197-213.

Fallows, J. (1996). Breaking the news: How the media undermine American democracy. New York: Pantheon.

Garfinkel, S. (2000). Database nation: The death of privacy in the 21st century. Sebastopol, CA: O'Reilly Media.

Gilbert, D. T., Krull, D. S., \& Malone, P. S. (1990). Unbelieving the unbelievable: Some problems in the rejection of false information. Journal of Personality and Social Psychology, 59(4), 601-613.

Gleick, J. (2000). Faster: The acceleration of just about everything. New York: Vintage Books. Grossman, L. K. (1995). The electronic republic. New York: Penguin Books.

Hargittai, E. (2010). Digital na(t)ives? Variation in internet skills and uses among members of the "net generation." Sociological Inquiry, 80(1), 92-113.

Hargittai, E., \& Shafer, S. (2006). Differences in actual and perceived online skills: The role of gender. Social Science Quarterly, 87(2), 432-448.

Hertsgaard, M. (1989). On bended knee: The press and the Reagan presidency. New York: Schocken Books.

Hoffman, D. L., \& Novak, T. P. (1996). Marketing in hypermedia computer-mediated environments: Conceptual foundations. Journal of Marketing, 60(3), 50-68. 
Howard, P. N. (2005). New media campaigns and the managed citizen. New York: Cambridge University Press.

Jenkins, H. (2008). Convergence culture: Where old and new media collide. New York: NYU Press.

Kalyanaraman, S., \& Wojdynski, B. W. (2015). Affording control: How customization, interactivity, and navigability affect psychological responses to technology. In S. S. Sundar (Ed.), The handbook of the psychology of communication technology (pp. 425444). New York: Wiley-Blackwell.

Kelly, K., \& Wolf, G. (1997, March 1). Push! Kiss your browser goodbye: The radical future of media beyond the Web. Wired. Retrieved from https://www.wired.com/1997/03/ff-push/

Lasswell, H. D. (1948). The structure and function of communication in society. In L. Bryson (Ed.), The communication of ideas (pp. 37-51). New York: Harper \& Row.

Markoff, J. (2016, November 17). Automated pro-Trump bots overwhelmed pro-Clinton messages, researchers say. The New York Times. Retrieved from https://www.nytimes.com/2016/11/18/technology/automated-pro-trump-botsoverwhelmed-pro-clinton-messages-researchers-say.html

Matthews, N. L., \& Weaver, A. J. (2013). Skill gap: Quantifying violent content in video game play between variably skilled users. Mass Communication and Society, 16, 829-846. McChesney, R. W. (2015). Rich media, poor democracy: Communication politics in dubious times (rev. ed.). New York: The New Press.

Morris, M., \& Ogan, C. (1996). The Internet as mass medium. Journal of Communication, 46(1), 39-50.

Mutz, D. C. (2015). In-your-face politics: The consequences of uncivil media. Princeton: Princeton University Press. 
Newhagen, J. E., \& Bucy, E. P. (2004). Routes to media access. In E. P. Bucy \& J. E. Newhagen (Eds.), Media access: Social and psychological dimensions of new technology use (pp. 3-23). Mahwah, NJ: Lawrence Erlbaum Associates.

Newhagen, J. E., \& Levy, M. R. (1998). The future of journalism in a distributed communication architecture. In D. L. Borden \& K. Harvey (Eds.), The electronic grapevine: Rumor, reputation, and reporting in the new online environment (pp. 9-21). Mahwah, NJ: Lawrence Erlbaum Associates.

Nowak, K., Krcmar, M., \& Farrar, K. (2008). The causes and consequences of presence: Considering the influence of violent video games on presence and aggression. Presence: Teleoperators \& Virtual Environments, 17(3), 256-268.

Ophir, E., Nass, C., \& Wagner, A. D. (2009). Cognitive control in media multitaskers. PNAS, 106(37), 15583-15587.

Papacharissi, Z. (2015). Affective publics: Sentiment, technology, and politics. New York: Oxford University Press.

Rheingold, H. (2002). Smart mobs: The next social revolution. New York: Basic Books.

Rheingold, H. (2014). Net smart: How to thrive online. Cambridge, MA: MIT Press.

Rojas, V., Straubhaar, J., Roychowdhury, D., \& Okur, O. (2004). Communities, cultural capital, and the digital divide. In E. P. Bucy \& J. E. Newhagen (Eds.), Media access: Social and psychological dimensions of new technology use (pp. 107-130). Mahwah, NJ: Lawrence Erlbaum Associates.

Rosen, J. (2001). The unwanted gaze: The destruction of privacy in America. New York: Vintage Books.

Shneiderman, B. (2000). Universal usability. Communications of the ACM, 43(5). 85-91.

Silverman, (2016, November 16). This analysis shows how viral fake election news stories outperformed real news on Facebook. Buzzfeed. Retrieved from 
https://www.buzzfeed.com/craigsilverman/viral-fake-election-news-outperformed-realnews-on-facebook

Stoll, C. (1995). Silicon snake oil: Second thoughts on the information superhighway. New York: Anchor Books.

Stromer-Galley, J. (2014). Presidential campaigning in the Internet age. New York: Oxford University Press.

Van Dijk, J. (2000). Widening information gaps and policies of prevention. In K. L. Hacker \& J. van Dijk (Eds.), Digital democracy: Issues of theory \& practice (pp. 166-183). London: Sage.

Van Dijk, J. (2005). The deepening divide: Inequality in the information society. Thousand Oaks, CA: Sage.

Van Dijk, J. (2012). The network society, 3rd ed. Thousand Oaks, CA: Sage.

Wertime, D. (2016, May 19). Meet the Chinese trolls pumping out 488 million fake social media posts: New research exposes a "massive secretive operation" to fill China's internet with propaganda. Foreign Policy. Retrieved from http://foreignpolicy.com/2016/05/19/meetthe-chinese-internet-trolls-pumping-488-million-posts-harvard-stanford-ucsd-research/

Zelenkauskaite, A., \& Bucy, E. P. (2016). A scholarly divide: Social media, Big Data, and unattainable scholarship. First Monday, 21(5). http://dx.doi.org/10.5210/fm.v21i5.6358 


\section{Endnotes}

${ }^{1}$ Rheingold (2002) years earlier made similar, though less theoretically grounded, observations in favor of the "ad-hocratizing" potential of mobile technology to facilitate temporary clustering around information or action agendas of mutual interest. More recently, he has written about the importance of digital literacy, including strategies for enhancing networked attention, participation, critical consumption of information ("crap detection"), and what he labels network smarts (Rheingold, 2014).

${ }^{2}$ A problem compounded by Trump's own tendency to spout, both verbally and through Twitter, daily barrages of false claims, especially while campaigning (Dale, 2016).

${ }^{3}$ The year 1996 was a watershed in two respects. First, the landmark Telecommunications Act of 1996 deregulated the cable industry and opened the door for unprecedented consolidation in television and radio, paving the way for the formation of Fox News and conservative control of talk radio (McChesney, 2015). The presidential election of 1996 was also the first in which campaign activities and information sources began to migrate online, promoting a managedand ultimately hyperpartisan-approach to citizenship (Howard, 2005; Stromer-Galley, 2014). ${ }^{4}$ Newhagen and Levy (1998, p. 17) anticipated this quandary when the shift to online news platforms began in earnest, observing that, "[I]t is difficult to imagine how this verification function might work in a distributed architecture and, in its absence, the burden of verification may thus shift back to the audience. Interactive information searches will call on users to employ a set of highly effortful cognitive skills they may not now possess."

${ }^{5}$ At the same time, many television shows, particularly in the prime-time drama, public affairs, talent competition, and game show genres, are incorporating feedback mechanisms that allow the viewing audience to engage more with the program hosts, show characters, contestants, or even other viewers either in real-time or asynchronously through activities on second screens, 
fan pages, show websites, text-on-television, telephone call-ins, and so on, creating rich "transmedia" experiences (see Beyer, Enli, Masso, \& Ytreberg, 2007; Evans, 2008).

${ }^{6}$ Mindful of this problem, interactive companies like Chicago-based Jellyvision (creators of the You Don't Know Jack trivia game) have developed "conversational interfaces" that talk users through "big life decisions, like selecting a health insurance plan, saving for retirement, managing finances, and navigating a career. Our recipe: behavioral science, cutting-edge tech, great writing, purposeful humor, original animation, and oregano." The system works by allowing visitors to "interact in real-time with a virtual host or advisor who talks directly to you and helps you understand complicated stuff and make smarter decisions" (see www.jellyvision.com). 